\title{
Malignant Skull Base Neoplasm
}

National Cancer Institute

\section{Source}

National Cancer Institute. Malignant Skull Base Neoplasm. NCI Thesaurus. Code C155791.

A primary or metastatic malignant neoplasm that affects the skull base. 